Vol. 40(1), pp. 1-15, June 2021

ISSN 1821-536X (print)

ISSN 2619-8789 (electronic)
Tanzania Journal of Engineering and Technology

Copyright (c) 2021 College of Engineering and

Technology, University of Dar es Salaam

Full length Research Paper

\title{
Rheological Properties of Aged Crude Hard Wood Pyrolysis Oil
}

\author{
Divina D. Kaombe
}

Department of Chemical and Mining Engineering, University of Dar es Salaam, Tanzania Corresponding author: divinakaombe@udsm.ac.tz or divinakaombe@gmail.com

\begin{abstract}
Upon storage of the pyrolysis oil, aging reactions may initiate phase separation and change of the rheological properties. These changes lead to unfavourable fuel characteristics in handling, transportation and applications. Efforts have been made for alleviation including methods on how to avoid these aging effects and development of equipment capable of handling aged pyrolysis liquids with unfavourable fuel characteristics. Therefore, the aim of this study was to explore the rheological properties of phase separated pyrolysis liquid fuel. Two batches of a well - stored poplar wood pyrolysis oils were used for the investigation; one batch was diluted with water to represent the oils undergoing severe phase separation (forced phase separation), and another batch was not diluted. Steady and dynamic rheological tests were conducted at various temperatures. Homogeneous (whole oil) and the bottom phases of pyrolysis oils were used. Results revealed that the whole oils of both diluted and undiluted oils exhibited low viscosity Newtonian behaviours at higher temperatures and high viscosity non-Newtonian behaviours at low temperatures. The bottom phases of both diluted and undiluted oils exhibited nonNewtonian behaviours with significant higher viscosity than the whole oils. The strain and frequency sweep dynamic tests showed existence of weak structures in the whole oils and strong network structures in the bottom phases. This study suggests that the handling, transportation and application of the pyrolysis oils undergoing phase separation are possible when the oils are treated with higher temperatures predominantly in turbulent state.
\end{abstract}

Keywords: Pyrolysis oils, whole oils, bottom phases, bottom fractions, phase separation, oligomers.

\section{INTRODUCTION}

Aged pyrolysis oils coupled with phase separation have complex rheological properties that lead to complications in handling, transportation and application. Researchers have reported a number of problems associated with using phase separating pyrolysis oils during oils' combustion tests including plugging of filter and nozzle at low feeding temperature, agglomeration of structures in oil recirculation systems, and sticking and jamming of the injection system when the operation stops (Ba et al., 2004a; Ba et al., 2004b; Panchasara and Ashwath, 2021). 


\section{Rheological Properties of Aged Crude Hard Wood Pyrolysis Oil}

The pyrolysis oils undergo a number of chemical reactions on storage leading to instability and phase separation. Polymerizations of lignin derived phenolic compounds are the main chemical reactions involved that lead to the formation of high molecular weight oligomers (molecular weight $\sim 5000$ or more) and water (Wang and Ben, 2020; Nolte and Liberatore, 2011; Fratini et al., 2006; Diebold, 2000). Stability range of the pyrolysis oil is $15-30 \mathrm{wt} \%$ dissolved water; excess water above this range causes precipitation of the ligninderivative molecules (oligomers). The aggregation of the oligomers and the increase in water above the oils' stability range lead to the phase separation. The phase separated pyrolysis oil consists of a light aqueous top phase and viscous tarlike organic bottom phase (Oasmaa et al., 2016; Fratini et al., 2006; Ba et al., 2004a; Diebold, 2000; Oasmaa and Czernik, 1999). In addition to this, longer storage period of the phase separating pyrolysis oils turns the viscous tar-like bottom phase into a gummy material resulting into a carbonaceous solid (Oasmaa et al., 2016; Oasmaa and Czernik. 1999). Therefore, it is interesting to understand and demonstrate the rheological properties of the aged pyrolysis oils.

The rheological properties of pyrolysis oils have been previously reported (Black and Ferrell, 2020; Jampolski et al., 2017; Tangsathitkulchai et al., 2012; Abdullah and $\mathrm{Wu}, 2011$; Abdullah et al., 2010; Nolte and Liberatore, 2010; ThangalazhyGopakumar et al., 2010; Qiang et al., 2009; Garcìa-Pérez et al., 2008; Ingram et al., 2008; Tzanetakis et al., 2008; GarcìaPérez et al., 2006). However, most of the studies have focused on the rheological properties of the whole pyrolysis oils. In these studies, the change in viscosity of the whole pyrolysis oils with time were investigated to demonstrate the storage stability of the pyrolysis oils (Black and Ferrell, 2020; Nolte and Liberatore, 2011;
Qiang et al., 2008; Yu et al., 2007; Oasmaa and Kuoppala, 2003; Boucher et al., 2000; Czernik et al., 1994), nevertheless the effect of the phase separation on the rheological properties of the resulting phases were not addressed. The rheological properties of the phase separating pyrolysis oils on storage particularly the resulting phases have not been explored before. Furthermore, homogenization of the phases without heat treatment has been a challenge. These are the problems addressed in this study.

In this study, well-stored popler wood pyrolysis oil was used for the investigation. The rheological study was conducted to the whole oils before phase separation and bottom phases after phase separation, at three different temperatures. The aim was to understand and demonstrate changes in the rheological properties of the oils before and after the phase separation, and investigate the influence of temperature on the rheological behaviours of the oils.

\section{METHODS AND MATERIALS}

\section{Materials}

Well stored pyrolysis oils from poplar wood ( 0.96 wt \% solids content) were used in this study. The pyrolysis oil samples were grouped into two; one group of samples was pyrolysis oil without dilution $(0$ wt $\%)$ and the second group was samples diluted with water $(10 \mathrm{wt} \%)$ in order to force phase separation. Selection of this dilution was based on the nature of the samples and preliminary study, whereby this dilution provided required stability for observation. A 0 wt $\%$ represented undiluted pyrolysis oil which is relatively stable and $10 \mathrm{wt} \%$ represented severely aged pyrolysis oil. 


\section{Sample Preparation}

Homogenization of samples was done at $60^{\circ} \mathrm{C}$ using a four bladed propeller at a speed of $500 \mathrm{rpm}$ for 20 minutes. There were two sets of samples for the rheological studies: (1) homogeneous pyrolysis oils before the phase separation (the whole oil); (2) bottom phases of the pyrolysis oil after the phase separation (bottom phases). For the rheological studies of the whole oil, the samples were introduced into a rheometer soon after homogenization whereas, for the rheological studies of the bottom phases the bottom phases of the phase separated oil were introduced into the rheometer soon after removing the top phase. The phase separation was performed by storing the samples for $24 \mathrm{~h}$ at 25,40 and $60^{\circ} \mathrm{C}$. Note that, the bottom phases represent behaviours of the sticky/gel like part of the oils after phase separation.

There were also measurements of the bottom phase fractions using a Turbiscan Lab, whereby the samples were introduced into a Turbiscan Lab soon after homogenization (the whole oil). Figure 1 shows the summary of the samples used for the whole study.

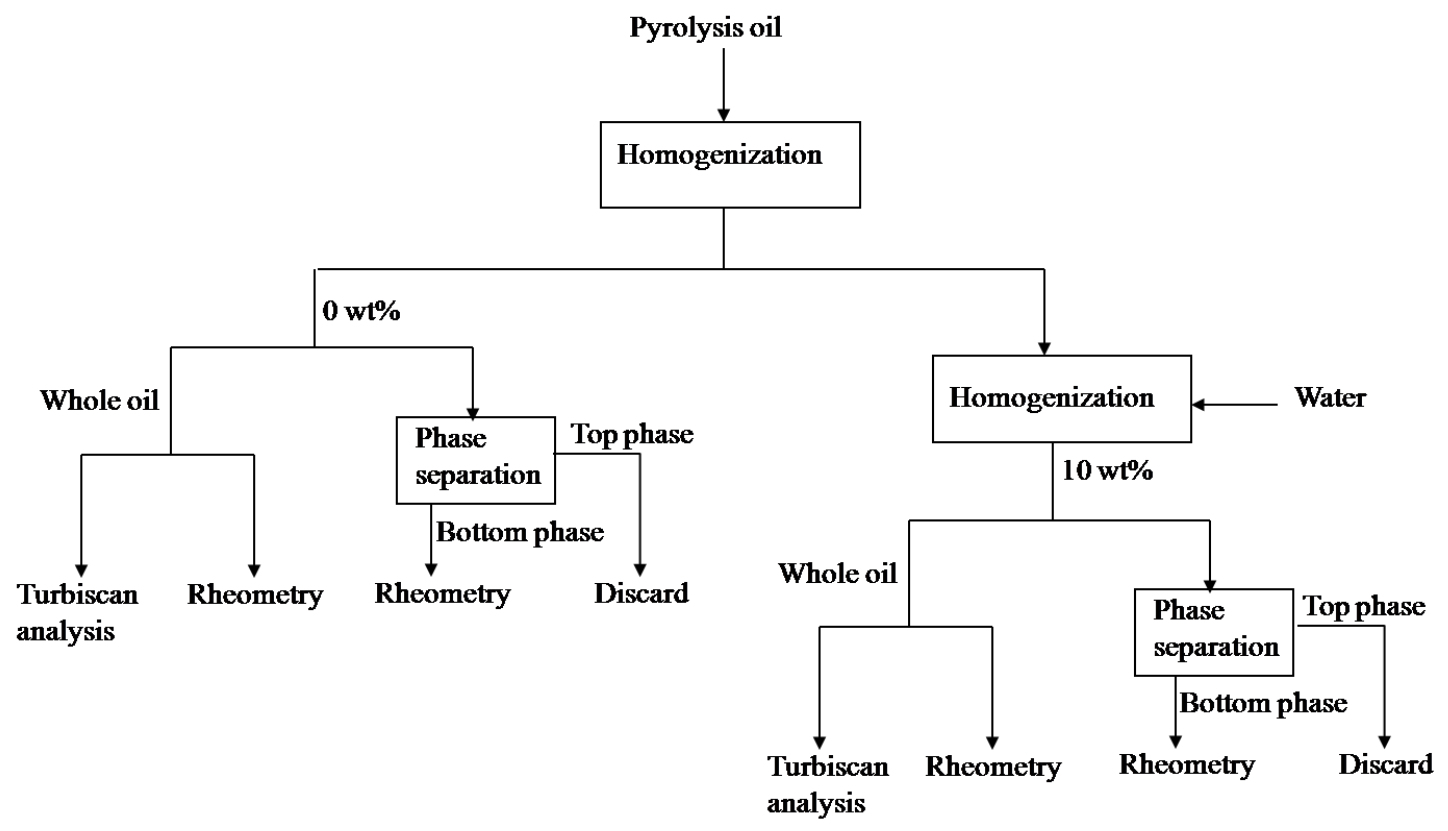

Figure 1: Schematic representation of the sample preparation for the analysis

\section{Bottom Phase Fraction \\ Measurements}

In the phase separated system, phase fraction can be calculated based on the quantity of the particular phase over the whole system. It can be upper, middle or bottom phase fraction depends on the number of phases formed in the system. In this study the focus was on the bottom phase fractions and they were calculated on the volume bases. The bottom phase fractions were estimated by Turbiscan Lab Expert 1.13 (manufactured by formulaction,
France). This is a tool for analysing the stability and phase separation of dispersions. In this work $20 \mathrm{ml}$ of each whole oil samples were scanned every 6 $\min$ for $24 \mathrm{~h}$, and the analysis were done at 25,40 and $60^{\circ} \mathrm{C}$. Figure 1 shows the samples that were subjected to Turbiscan analysis.

\section{Rheological Studies (Rheometry)}

The rheological properties of the pyrolysis oils were measured using a Physca MCR 301 rheometer (Anton Paar) with two geometries: 
concentric cylinder CC27/E geometry (cup diameter $28.920 \mathrm{~mm}$, bob diameter $26.66 \mathrm{~mm}$, bob gap length $40.021 \mathrm{~mm}$ ); (2) cone and plate CP50-2 geometry (cone diameter $49.974 \mathrm{~mm}$, cone angle $2.011^{\circ}$, cone truncation $\left.52 \mu \mathrm{m}\right)$. Torque limit for the Physca MCR 301 rheometer is $0.1 \mu \mathrm{Nm}$ minimum and $200 \mathrm{mNm}$ maximum. Therefore, the selection of the geometry to be used was based on the nature of the samples and torque values observed in the study. Experimentation was performed on the whole oil and bottom phases at 25, 40 and $60^{\circ} \mathrm{C}$ under steady and dynamic state conditions. For the steady shear condition, the oil samples were sheared prior to the measurements at a constant rate of $50 \mathrm{~s}^{-1}$ for 2 minutes to allow equilibrium between the sample and the set temperature. This was followed by measuring the flow curves at shear rate range of $1-1000 \mathrm{~s}^{-1}$ in 5 minutes and $1000-1 \mathrm{~s}^{-1}$ in 5 minutes at a constant temperature. For the dynamic shear condition there were strain sweep tests and frequency sweep tests. In every test the oil samples were left unsheared for 2 minutes for the temperature equilibrium, followed by (1) the strain sweep test $(0.0001-100 \%)$ at a frequency of $1 \mathrm{~Hz}$; (2) the frequency sweep test $(1-100 \mathrm{~Hz})$ at strain of $1 \%$, during these tests the temperature was kept constant.

\section{RESULTS AND DISCUSSION}

\section{Magnitudes of the Bottom Phases}

In the rheological studies the focus is on the interaction of the particles; strong interaction of the particles leads to elastic or strong viscoelastic behaviours while weak interaction leads to viscous/fluid or weak viscoelastic properties. While the rheological studies are based on the interactions of the particles, the interactions strongly depend upon the concentration of the particles. The concentration and interactions of the particles in the bottom phases are also affected by the degree of the phase separation and temperature. However, it is not clear if there is any relationship between them. For example, a sample may have a higher bottom fraction, but less concentration of the particles resulting into weak interactions while another sample may have a lower bottom fraction, but high concentration of the particles resulting into strong interactions. In this study the bottom fractions of the pyrolysis oils were investigated, which will later be related with moduli values of the respective bottom phases.

The bottom fractions were analysed by using the Turbiscan method and results are shown in Figure 2. The diluted pyrolysis oils (10 wt\%) appear to have relatively high bottom fractions ranging between $31-27$ vol\% while the bottom fractions of the undiluted pyrolysis oils $(0 \mathrm{wt} \%)$ range between $21-6 \mathrm{vol} \%$. The higher bottom fractions observed for the diluted pyrolysis oils $(10 \mathrm{wt} \%)$ is because of the faster phase separation due to the difference in polarity and solubility between the aqueous continuous phase and suspended phase of lignin-derived compounds (Kaombe et al., 2013). Investigation of the effect of temperature shows that formation of the bottom phases for the diluted pyrolysis oils (10 wt \%) decreased with temperature in a well-defined trend; the bottom fractions decreased with temperature because of the dissolution of lignin decomposition products at higher temperature (Ba et al., 2004b). However, for the undiluted pyrolysis oils $(0 \mathrm{wt} \%)$, the trend was not uniform; the highest bottom fractions were at $40^{\circ} \mathrm{C}$ and the lowest were at $25^{\circ} \mathrm{C}$. The decrease in the bottom fractions for the undiluted pyrolysis oils ( $0 \mathrm{wt} \%$ ) at $25^{\circ} \mathrm{C}$ is due to the slower phase separation. 


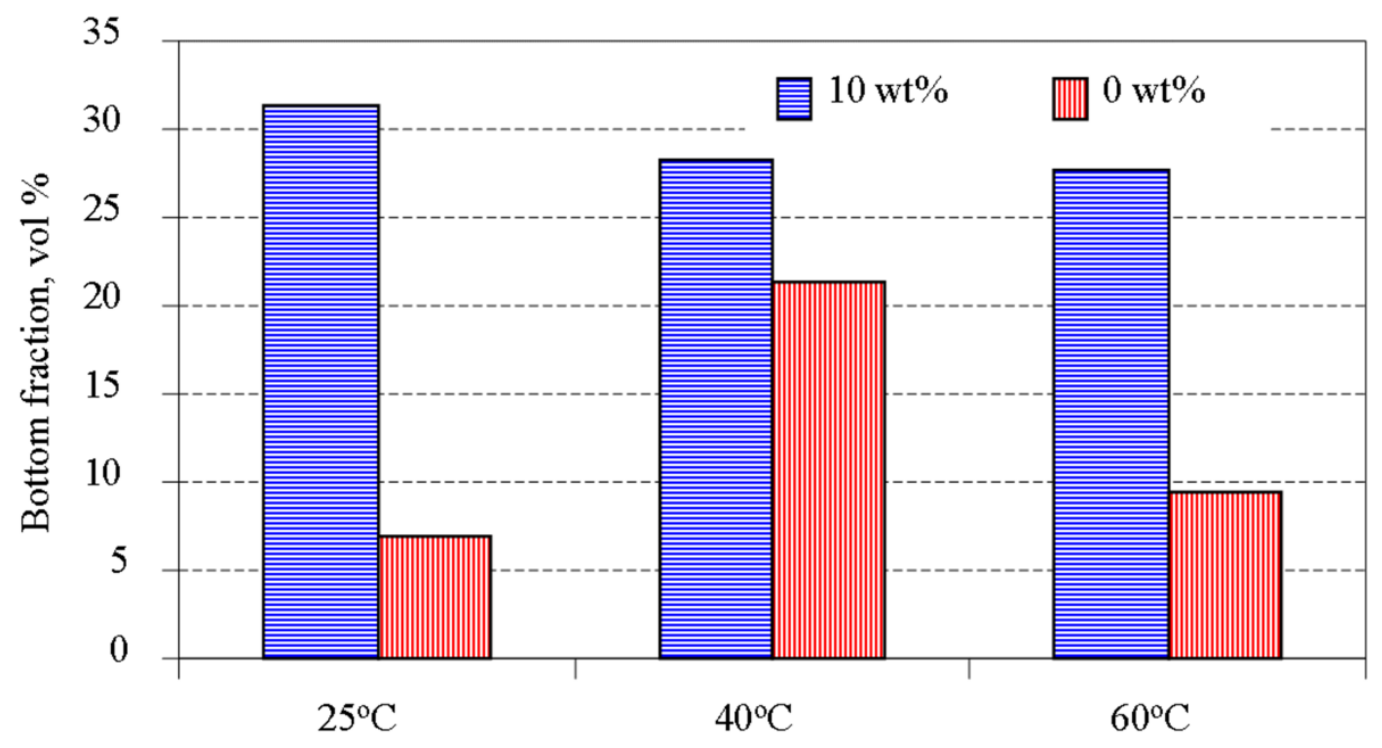

Figure 2: Bottom fraction concentration of the undiluted $(0 \mathrm{wt} \%)$ and diluted $(10 \mathrm{wt} \%)$ pyrolysis oils at 25,40 and $60^{\circ} \mathrm{C}$.

\section{Steady State Rheological Studies}

\section{Flow behaviour of the whole oil}

Figure 3 shows the flow behaviour study for the whole oils at 25,40 and $60^{\circ} \mathrm{C}$. In this study the Newtonian behaviour dominated to all pyrolysis oils except for the undiluted pyrolysis oils $(0 \mathrm{wt} \%)$ at $25^{\circ} \mathrm{C}$ where the viscosity was not constant over applied shear. The variation of viscosity over applied shear is the typical behaviour of the structured fluids or suspensions (colloidal systems). Colloidal systems like pyrolysis oils are considered to be structured fluids because of having multiphase structures, and their rheology is determined by the interactions of the components which causes complex flow behaviour. In this case the flow behaviour is comprised of various flow behaviours simultaneously. Initially the shear thinning behaviour can be observed, followed by the Newtonian behaviour and then the shear thickening behaviour. At the beginning of the shearing of the pyrolysis oils there is a breakage of the agglomerated chars and three-dimensional compounds like aggregated oligomers that leads to the shear thinning behaviour. The Newtonian behaviour follows when a twodimensional arrangement parallel to the shear planes appears. The shear thickening behaviour occurs at higher shear rates due to a formation of the temporary aggregates or structure disorder (Tzanetakis et al., 2008; Raghan and Khan, 1995). The aggregation of these structures are responsible for the sticky like behaviour when the oils are handled or transported, hence the increase in viscosity with resultant deviation from Newtonian to non-Newtonian flow behaviour (GarcìaPérez et al., 2008; Diebold, 2000). At 40 and $60^{\circ} \mathrm{C}$ the undiluted pyrolysis oils $(0 \mathrm{wt}$ $\%$ ) behaved more like Newtonian fluid because they were in a structure dissolution temperature range which is 30 $-60^{\circ} \mathrm{C}$ (Czernik and Bridgwater, 2004). Despite of behaving like Newtonian fluid, samples exposed to $40^{\circ} \mathrm{C}$ exhibited shear thickening at higher shear rates $\sim 100 \mathrm{~s}^{-1}$. This is probably due to the hydrodynamic interaction of undissolved structures at higher shear rates giving rise to shear 


\section{Rheological Properties of Aged Crude Hard Wood Pyrolysis Oil}

thickening (Zaman et al., 1996). The shear thickening behaviour may pose a problem in handling, transportation and applications of the oil such as mixer blade damage, mixer motor overloading, complications in pipe flow, etc. (Bosco et al., 2019).

In all cases the viscosity of the diluted pyrolysis oils (10 wt \%) was lower than the undiluted pyrolysis oils $(0$ wt $\%)$. For example, at $25^{\circ} \mathrm{C}$ the viscosity of the diluted pyrolysis oils $(10 \mathrm{wt} \%)$ was $0.016 \mathrm{~Pa}$.s while the undiluted pyrolysis oils ( 0 wt \%) was in the order of $\sim 0.1$ Pa.s. This is because the dilution lowers the volume fraction of the suspended particles and increases the surface-surface separation. Furthermore, the plot shows that the pyrolysis oils treated at higher temperatures appear to have relatively low viscosity. For example, the viscosity of the undiluted pyrolysis oil samples $(0 \mathrm{wt} \%)$ at 25,40 and $60^{\circ} \mathrm{C}$ is in the order of $\sim 0.1$, 0.04 and 0.02 Pa.s, respectively. Czernik and Bridgwater (2004) have reported that, the viscosity of the pyrolysis oils decreases much faster than petroleum-derived oils at higher temperature. In many applications it is a common practice to pre-heat pyrolysis oils because it makes pumping and stirring easier. One of the reasons for the decrease in viscosity at higher temperatures is due to the dissolution of the oligomers derived structures which happens at a temperature range of $30-60^{\circ} \mathrm{C}$ (Ba et al., 2004b). Furthermore, at higher temperatures the intermolecular forces such as hydrogen bonding are weak, leading to the viscosity reduction (Garcìa-Pérez et al., 2006). This is due to the fact that at higher temperature molecules attain higher kinetic energy, which enables them to overcome attractive forces that prevent the liquid from flowing.

Although all the oils treated with water (10 $\mathrm{wt} \%)$ and the oils exposed to higher temperatures (both $0 \mathrm{wt} \%$ and $10 \mathrm{wt} \%$ ) exhibited simple Newtonian behaviour, some exhibited shear thickening at higher shear rates. The shear thickening can be observed for the undiluted pyrolysis oil (0 $\mathrm{wt} \%)$ at $40^{\circ} \mathrm{C}$ and diluted pyrolysis oil (10 wt $\%)$ at 40 and $60^{\circ} \mathrm{C}$. The undiluted pyrolysis oils $(0$ wt $\%)$ are expected to have more structures because of higher concentration of the suspended particles, which leads to the complex flow behaviour. However, some of these structures dissolve into the oil matrix at a temperature range of $30-60^{\circ} \mathrm{C}$ which makes the oils deviates from the complex flow behaviour into simple Newtonian behaviour. At higher shear rates hydrodynamic interactions cause the remained undissolved structures to rearrange together with solids (chars) into temporary aggregates resulting into the shear thickening (Zaman et al., 1996). The rearrangement of the undissolved structures at higher shear rates can be the same reason for the shear thickening of the diluted pyrolysis oil $(10 \mathrm{wt} \%)$ at 40 and $60^{\circ} \mathrm{C}$. 


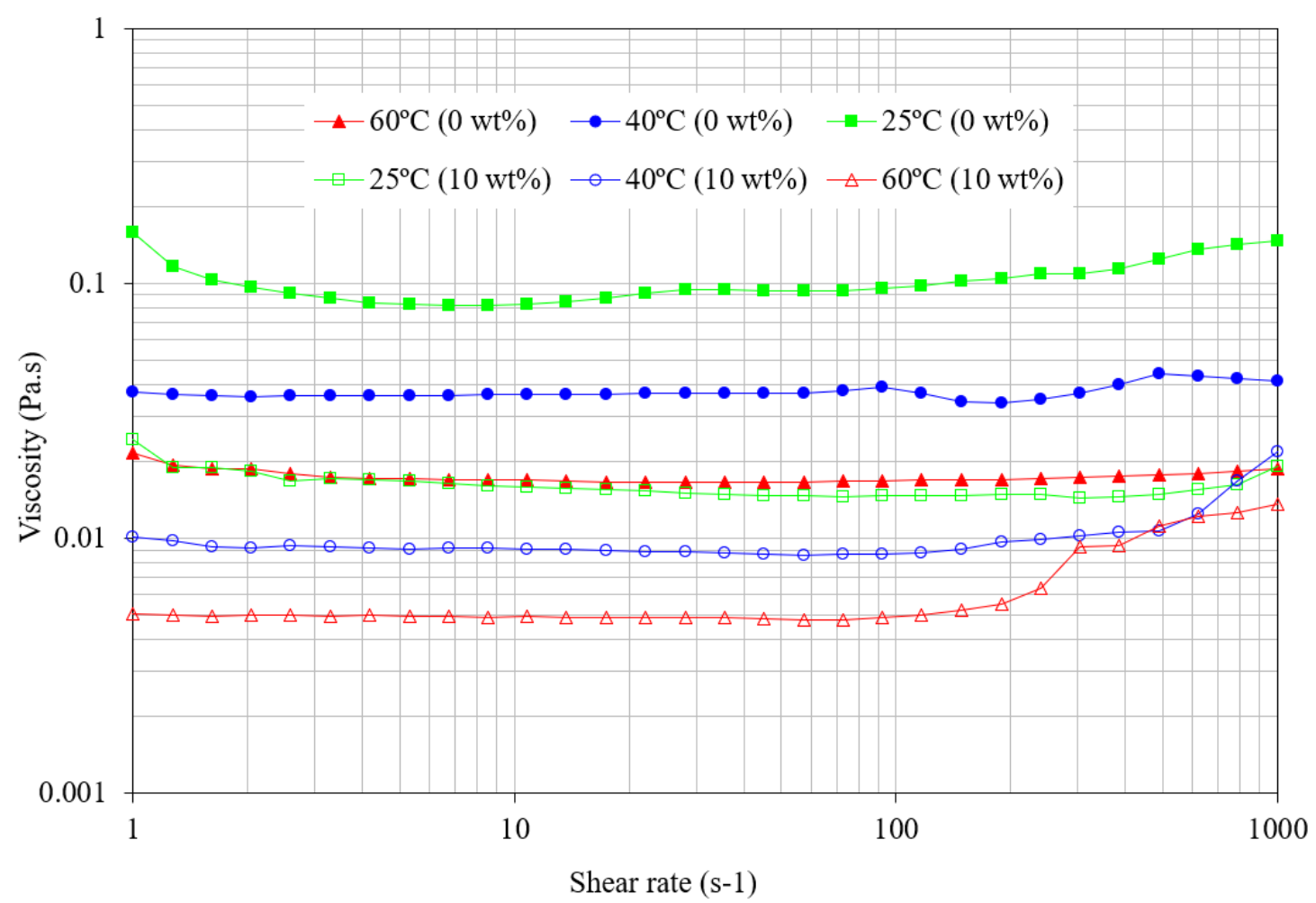

Figure 3: Viscosity of the whole pyrolysis oils as a function of the shear rate and temperature. Curves with solid dots represent data from the undiluted samples $(0$ wt \%), and curves with open dots represents data from the diluted samples $(10 \mathrm{wt} \%)$.

\section{Flow behaviour of the bottom phases}

In this study the flow behaviour tests for the bottom phases were performed using the cone and plate CP50-2 geometry. Figure 4 shows results for the bottom phases of the undiluted $(0 \mathrm{wt} \%)$ and diluted $(10 \mathrm{wt} \%)$ pyrolysis oils at 25,40 and $60^{\circ} \mathrm{C}$. The viscosities of the bottom phases are approximately ten times higher than the whole oil for the case of undiluted pyrolysis oils $(0 \mathrm{wt} \%)$ and a thousand times higher for the case of diluted pyrolysis oils (10 wt\%) (compare Figure 4 with Figure 3). The increase in viscosity for the bottom phases is due to the fact that the bottom phases of the pyrolysis oils have higher concentration of agglomerated heavy oligomers and chars, the viscous nature of the pyrolysis oils are mainly contributed by these structures (phase (Black and Ferrell, 2020; Nolte and Liberatore, 2011; Fratini et al., 2006; Ba et al., 2004a; Diebold, 2000; Oasmaa and Czernik. 1999).

All samples exhibited non-Newtonian behaviours by decreasing the viscosity with shear rate (as shown in Figure 3), which is a shear thinning behaviour. This behaviour is caused by the breakage of the structures on shearing, which is a common behaviour to concentrated suspensions (Mueller et al., 2010). At high concentration particles are close to each other which allow packing, interlocking and formation of structures. However, shearing process breaks the structures resulting into shear thinning behaviours. The shear thinning behaviour appeared to be very prominent for the bottom phases of the diluted pyrolysis oils (10 wt\%) mainly at $25^{\circ} \mathrm{C}$. The prominence of the shear thinning behaviour for these samples is caused by higher concentration of the particles: (1) dilution process forces majority of the dispersed oligomers and 
chars to settle down forming the bottom phases, (2) at low temperature $\left(25^{\circ} \mathrm{C}\right)$ particles do not dissolve in the oil matrix.

The effect of the temperature can also be observed in the plot, the bottom phases exposed to higher temperatures have relatively low viscosities. This is due to the weaker hydrogen bonding at higher temperatures leading to the reduction in viscosity. However, the trend was not consistent for the undiluted pyrolysis oils (0 wt\%), whereby the viscosity of the bottom phases at $40^{\circ} \mathrm{C}$ was higher than at $25^{\circ} \mathrm{C}$. At $40^{\circ} \mathrm{C}$ the phase separation is influenced by the temperature and storage time while at $25^{\circ} \mathrm{C}$ the phase separation depends solely on the storage time. Therefore, if the storage time or observation time is short then the bottom phases of the oils exposed to $40^{\circ} \mathrm{C}$ are likely to have more concentration of the particles than those exposed to $25^{\circ} \mathrm{C}$. At $60^{\circ} \mathrm{C}$ the viscosity is relatively low despite of the faster formation of the bottom phases. This might be due to the dissolution of the structures and weakening of hydrogen bonding at higher temperatures causing reduction of the viscosity (Ba et al., 2004b).

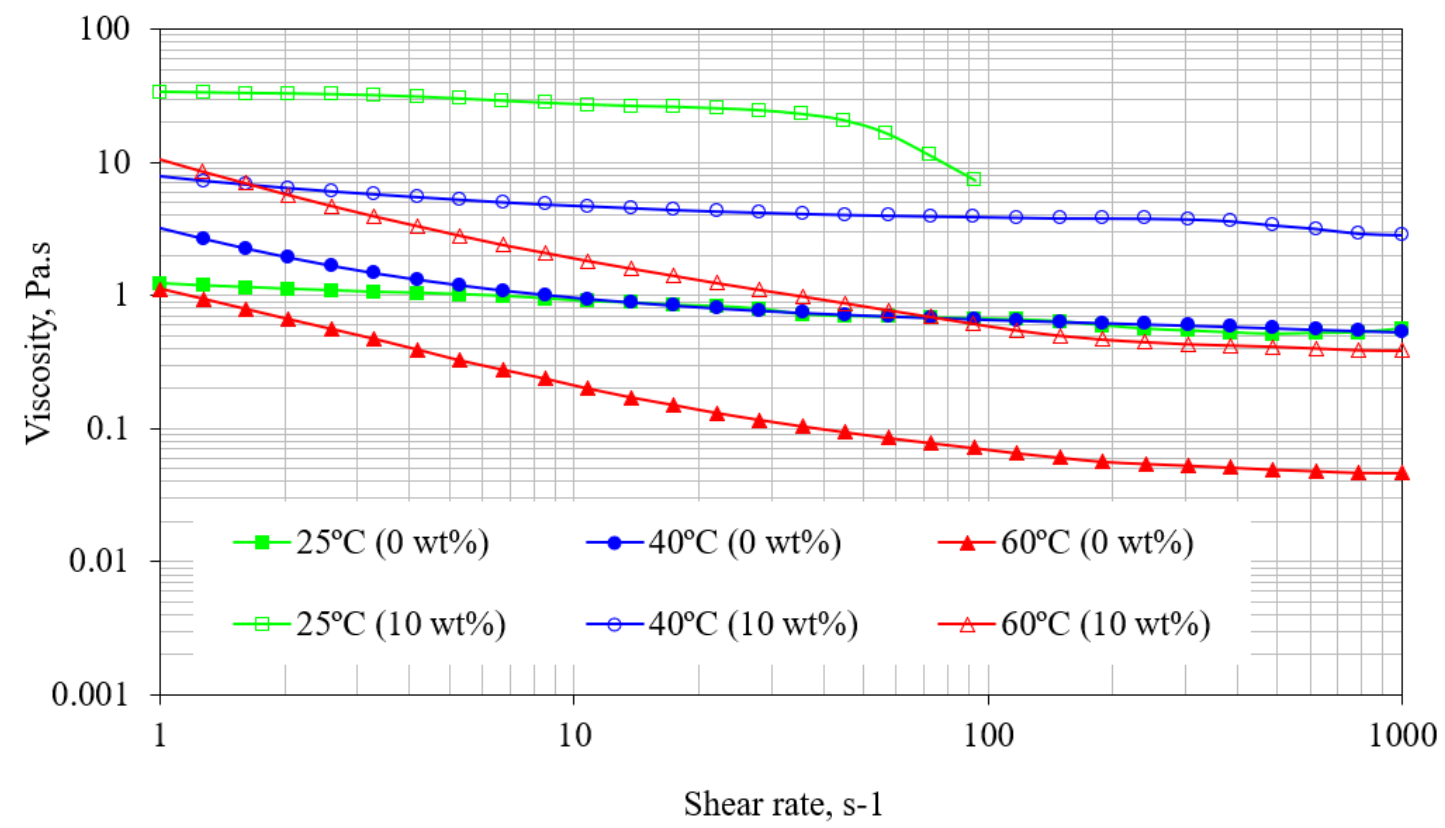

Figure 4: Viscosity of the pyrolysis oils bottom phases as a function of the shear rate and temperature. Curves with solid dots represent data from the undiluted samples bottom phases $(0 \mathrm{wt} \%)$, and curves with open dots represents data from the diluted samples bottom phases $(10 \mathrm{wt} \%)$.

\section{Dynamic Rheological Studies (Oscillatory Tests)}

The Oscillatory tests give supplementary information about the behaviour of the materials such as viscoelastic properties that are difficult to analyse in the steady rheological tests. In the steady rheological tests, the viscosity measurement is performed at a given shear rate, that means most of the structures get disrupted during these tests because of shearing, only uncomplicated instantaneous structures can be characterised. In the steady rheological tests results, the pyrolysis oils behaved partly like the non-Newtonian behaviours, indicating the probability of having structures. Examination of the structures' existence was later performed in the oscillatory/dynamic tests, where the 
strain sweep and frequency sweep tests were performed. The oscillatory tests were conducted to both the whole oils and bottom phases at 25,40 and $60^{\circ} \mathrm{C}$.

\section{Oscillatory tests for the whole oil}

The oscillatory tests for the whole oil were performed to the undiluted pyrolysis oils $(0$ wt $\%)$ only; because they partly exhibited non-Newtonian behaviours as shown in Figure 3. The analysis was done at 25,40 and $60^{\circ} \mathrm{C}$ using the cone and plate CP50-2 geometry. Figure 5 shows the strain sweep tests results, whereby the values of the storage and loss moduli are shown. The storage modulus (G') represent elastic behaviours while the loss modulus (G') represent viscous behaviours. At low strains most of the data were omitted due to the limitation of the Rheometer torque range. All samples exhibit decreases in $G^{\prime}$ values with strain while G" values remain constant, showing an absence of defined limit of viscoelastic region (whereby both the G' and G', values are constant with strain). Except at $25^{\circ} \mathrm{C}$ where the viscoelastic region is pronounced with low values of $\mathrm{G}^{\prime}$. This indicates the absence of network structures at higher temperatures. The strain independency observed at $25^{\circ} \mathrm{C}$ is due to the presence of aggregated oligomers that form weak structures with $G$ ' values in the order of $1 \mathrm{~Pa}$. At higher temperatures the $G$ ' values are very low essentially at low strains, this is more pronounced at $60^{\circ} \mathrm{C}$. A the deficiency of $G^{\prime}$ value is caused by the dissolution of structures at higher temperatures (Ba et al., 2004b). In addition, both moduli values decrease with temperature which reflects the Newtonian behaviour observed at higher temperatures during the steady rheological tests. In general, the pyrolysis oils (whole oils) behaved like Newtonian fluids as the values of the $G^{\prime}$ ' are greater than $G^{\prime}$, indicating that viscous behaviour dominates. This is a common behaviour for most woody product pyrolysis oils and has been reported in previous studies (Tzanetakis et al., 2008; Garcìa-Pérez et al., 2006). Although the G' values were very low, their presence shows the existence of some elastic behaviour; which can be better evaluated in frequency sweep tests.

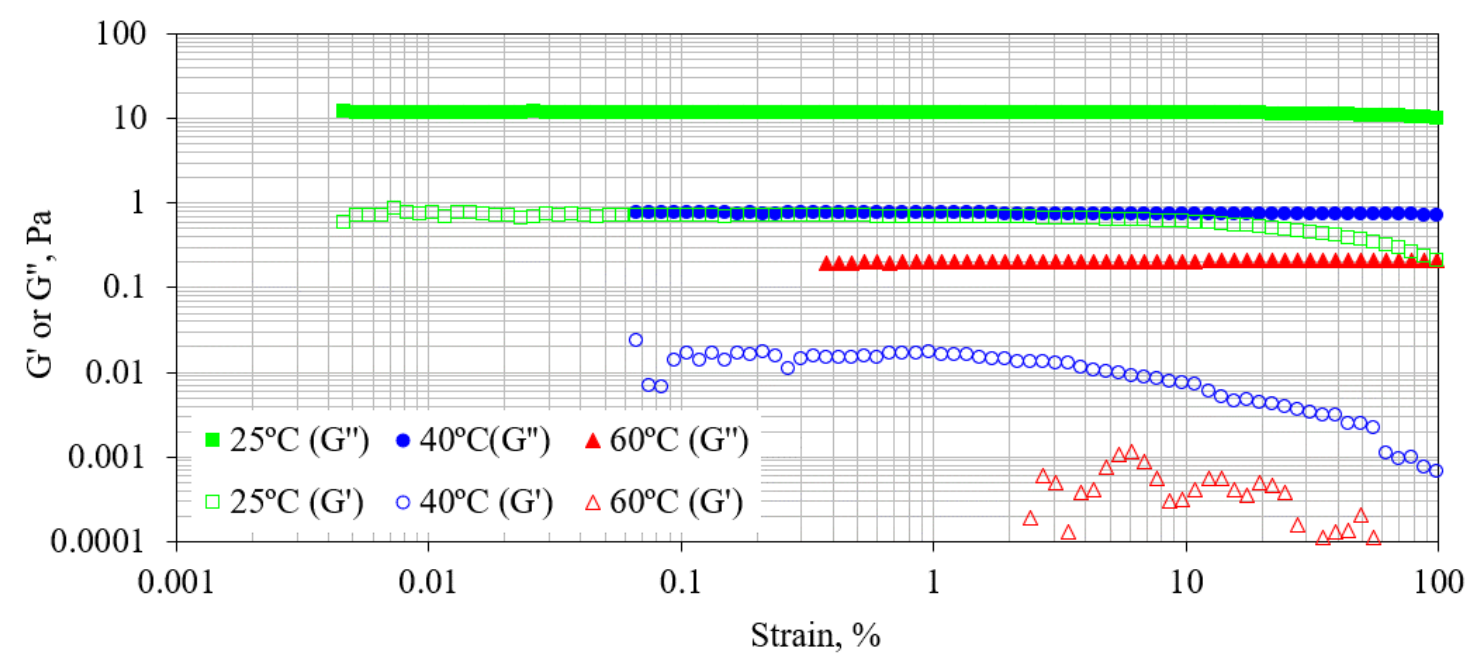

Figure 5: Dynamic strain sweeps at a frequency of $1 \mathrm{~Hz}$ for the whole oil- undiluted pyrolysis oils ( $(0 \mathrm{wt} \%)$.

The frequency sweep tests are commonly performed to characterize viscoelastic behaviours to supplement the strain sweep tests. These tests are performed at a strain beyond a critical strain where G' and G', values are non-linear and strain dependent. 


\section{Rheological Properties of Aged Crude Hard Wood Pyrolysis Oil}

Here the frequency sweep tests were performed at $1 \%$ strain (as shown in Figure 6). The analysis shows a strong frequency dependency of G' and G', with viscous behaviour dominating (G'>> G'), indicating the fluid behaviour dominating. Although the viscous behaviour dominates, the values of $G^{\prime}$ approach a slope of 2.0 while the values of $G$ ', approach a slope of 1.0 at the wide range of frequency essentially at higher frequencies, indicating presence of linear viscoelasticity (Tzanetakis et al., 2008; Garcì-Pérez et al., 2006). This reflects the steady shear rheology observed in Figure 3, whereby the Newtonian behaviour dominated with partly non-Newtonian behaviours. The highest values of $\mathrm{G}^{\prime}$ were in the order of $50-100 \mathrm{~Pa}$ while the highest values of the $G$ ", were in the order

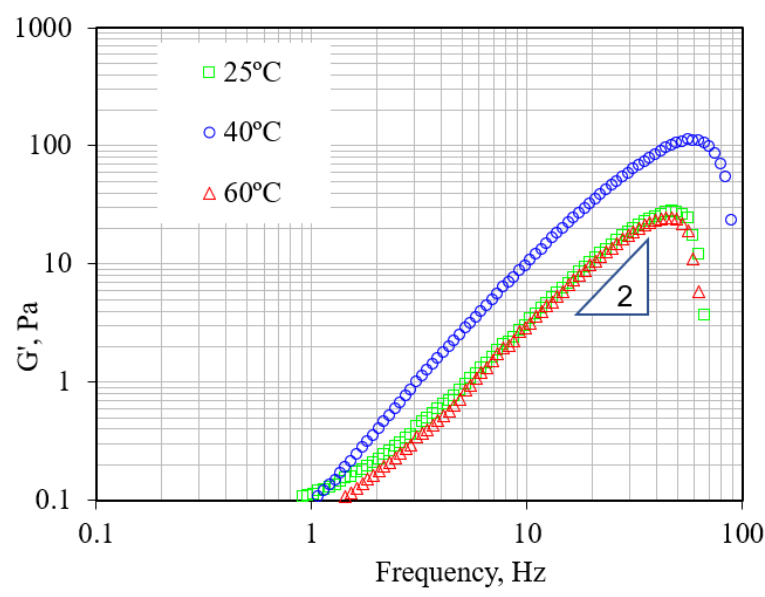

of $1000 \mathrm{~Pa}$, as observed in this study. This confirms that the pyrolysis oil is Newtonian fluid with some weak elastic behaviour. At higher frequencies of the range $\sim 70-100 \mathrm{~Hz}$ the $\mathrm{G}$ ' values appear to drop down to zero while the values of G' keep increasing and approach $1000 \mathrm{~Pa}$. This indicates that the formation of structures that exhibit the elastic behaviour does not happen instantly, while the formation of structures that exhibit viscous behaviour happen faster. Furthermore, the values of $G$ " decrease with temperature which was also observed in the strain sweep. This reflects the decrease in the steady shear viscosity with temperature. This suggests that the aging effects of the aged pyrolysis oil that hinder its applications can be alleviated by heating and well mixing the oil.

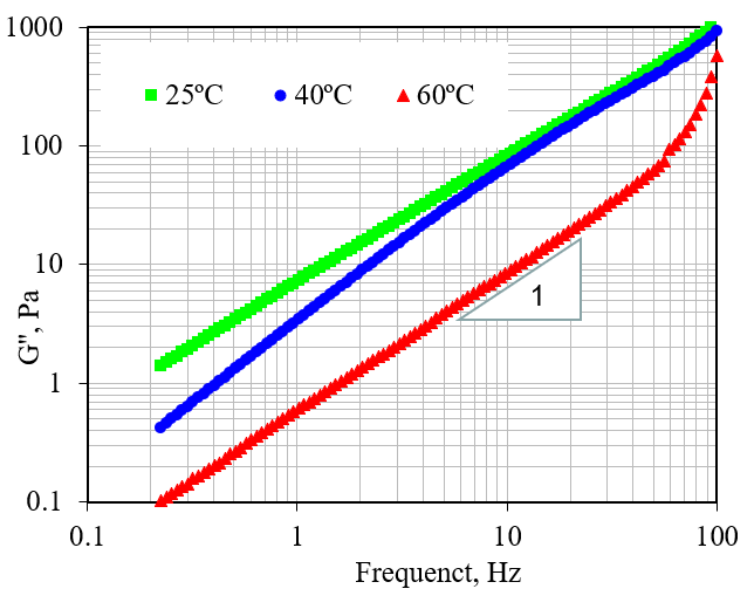

Figure 6: Dynamic frequency sweeps at $1 \%$ strain for the whole oil- undiluted pyrolysis oils (0 wt \%).

\section{Oscillatory tests for the bottom phases}

The study of the dynamic rheological properties for the bottom phases of the pyrolysis oils was performed to the bottom phases of the undiluted pyrolysis oils $(0 \mathrm{wt}$ $\%)$ and diluted pyrolysis oils (10 wt \%). Only strain sweep tests at a frequency of 1 $\mathrm{Hz}$ were performed using the cone and plate CP50-2 geometry. The analysis was done at 25,40 and $60^{\circ} \mathrm{C}$. Figure 7 shows the G' and G' "values of the bottom phases of the undiluted pyrolysis oils (0 wt \%). The values of the moduli for the bottom phases increased significantly compared to the values of the moduli of the whole oil of the undiluted pyrolysis oil $(0 \mathrm{wt} \%)$ as shown in Figure 5. The highest values are approximately 100 times higher than the whole oil of the undiluted pyrolys is oil ( 0 wt \%), except at $25^{\circ} \mathrm{C}$ where the moduli values increased very slightly (compare Figure 7 and 5). At $25^{\circ} \mathrm{C}$ the highest values of the G', and G' for the bottom phases are 
approximately $15.8 \mathrm{~Pa}$ and $2.5 \mathrm{~Pa}$, respectively, while for the whole oil are approximately $11.9 \mathrm{~Pa}$ and $0.8 \mathrm{~Pa}$, respectively. The significant increase in module values at higher temperatures is due to the fast phase separation resulting into higher concentration of the aggregated oligomers that interconnect to form stronger network structure in form of a gel in the bottom phases', while the slight increase of the moduli values at $25^{\circ} \mathrm{C}$ is due to the slow phase separation at low temperatures leading to low concentration of the aggregated oligomers in the bottom phases.

Furthermore, the observed lower values of moduli at $25^{\circ} \mathrm{C}$ indicate absence of network structure; the aggregated oligomers exist in the form of flocs. However, the strong network structure can be formed when the oils are left for longer storage period without stirring. The highest moduli values in the plot obtained at $40^{\circ} \mathrm{C}$ and the lowest values obtained at $25^{\circ} \mathrm{C}$ reflecting the bottom fractions of the undiluted pyrolysis oil ( $0 \mathrm{wt} \%)$ presented in Figure 2. In Figure 2 it was observed that the highest bottom fractions were obtained at $40^{\circ} \mathrm{C}$ and the lowest were obtained at $25^{\circ} \mathrm{C}$. This indicates that the bottom fraction represents the concentration of the particles. At $40^{\circ} \mathrm{C}$ there is higher concentration of particles which causes stronger interactions resulting into higher moduli values while at $25^{\circ} \mathrm{C}$ the concentration of the particles is lower which causes weaker interaction resulting into lower moduli values.

In all cases, the values of the $G^{\prime}$ and $G^{\prime}$ ' were observed to be close (except at $25^{\circ} \mathrm{C}$ ), indicating stronger viscoelastic behaviour. At $25^{\circ} \mathrm{C}$ the viscous behaviour dominates $\left(G^{\prime \prime}>>G^{\prime}\right)$ with no critical strain, indicating the prominence of the fluid behaviour, which is the similar behaviour observed to the whole oil. Furthermore, the plot shows that the G', values at higher strains $(\sim 20-100 \%)$ reflects the trend of the steady shear viscosity curves for the bottom phases of the undiluted pyrolysis oil (0 wt \%) (When Figure 7 and 4 are compared). The G', values are high at $40^{\circ} \mathrm{C}$ and low at $60^{\circ} \mathrm{C}$, similar to the steady shear study where the viscosities are high at $40^{\circ} \mathrm{C}$ and low at $60^{\circ} \mathrm{C}$. The similarity is due to the fact that at higher dynamic strains there is disruption of the network structure, which is the same thing that happens when shear measurements are done (Raghavan and Khan, 1995).

The G' and G' values for the bottom phases of the diluted pyrolysis oils (10 wt $\%)$ are presented in Figure 8 with $\mathrm{G}^{\prime}$ and $G$ " values being closer except at $25^{\circ} \mathrm{C}$. This closeness of $G^{\prime}$ and $G^{\prime \prime}$ values indicate strong viscoelastic behaviour. At $25^{\circ} \mathrm{C}$ the viscous behaviour dominates ( $G^{\prime}$ '> $G^{\prime}$ '), indicating that the bottom phases at this temperature behaves more like a liquid. Both the moduli values appear to decrease with temperature in a well-defined trend (higher values at $25^{\circ} \mathrm{C}$ and lower values at $60^{\circ} \mathrm{C}$ ) reflecting the bottom fractions presented in Figure 2. The lower moduli values at $60^{\circ} \mathrm{C}$ are due to the fact that at higher temperature some of the structures dissolve in the oil matrix, which leads to the low particle concentration in the bottom phase. Furthermore, at high temperatures the structures are weak because of weaker cross-linking agents such hydrogen bonds. The plot shows a clear region of linear viscoelasticity in all cases which ends at a strain of $\sim 1 \%$, (critical strain). Beyond the critical strain, the module values decrease with strain. When comparing with the bottom phases of the undiluted pyrolysis oils $(0 \mathrm{wt} \%)$ presented in Figure 7 , the $G^{\prime}$ and $G$ ' values of the bottom phases of the diluted pyrolysis oils $(10 \mathrm{wt} \%)$ are significantly high. The highest values of the G' and G', for the bottom phases of the diluted pyrolysis oils (10 wt\%) obtained at $25^{\circ} \mathrm{C}$ are in the order of $500 \mathrm{~Pa}$ and 1000 $\mathrm{Pa}$, respectively; while for the undiluted pyrolysis oils $(0 \mathrm{wt} \%)$ are in the order of 


\section{Rheological Properties of Aged Crude Hard Wood Pyrolysis Oil}

$200 \mathrm{~Pa}$ and $200 \mathrm{~Pa}$, respectively obtained at $40^{\circ} \mathrm{C}$. The rise in the moduli values for the diluted pyrolysis oils $(10 \mathrm{wt} \%)$ is due to the formation of highly concentrated bottom phases as a result of faster phase separation.

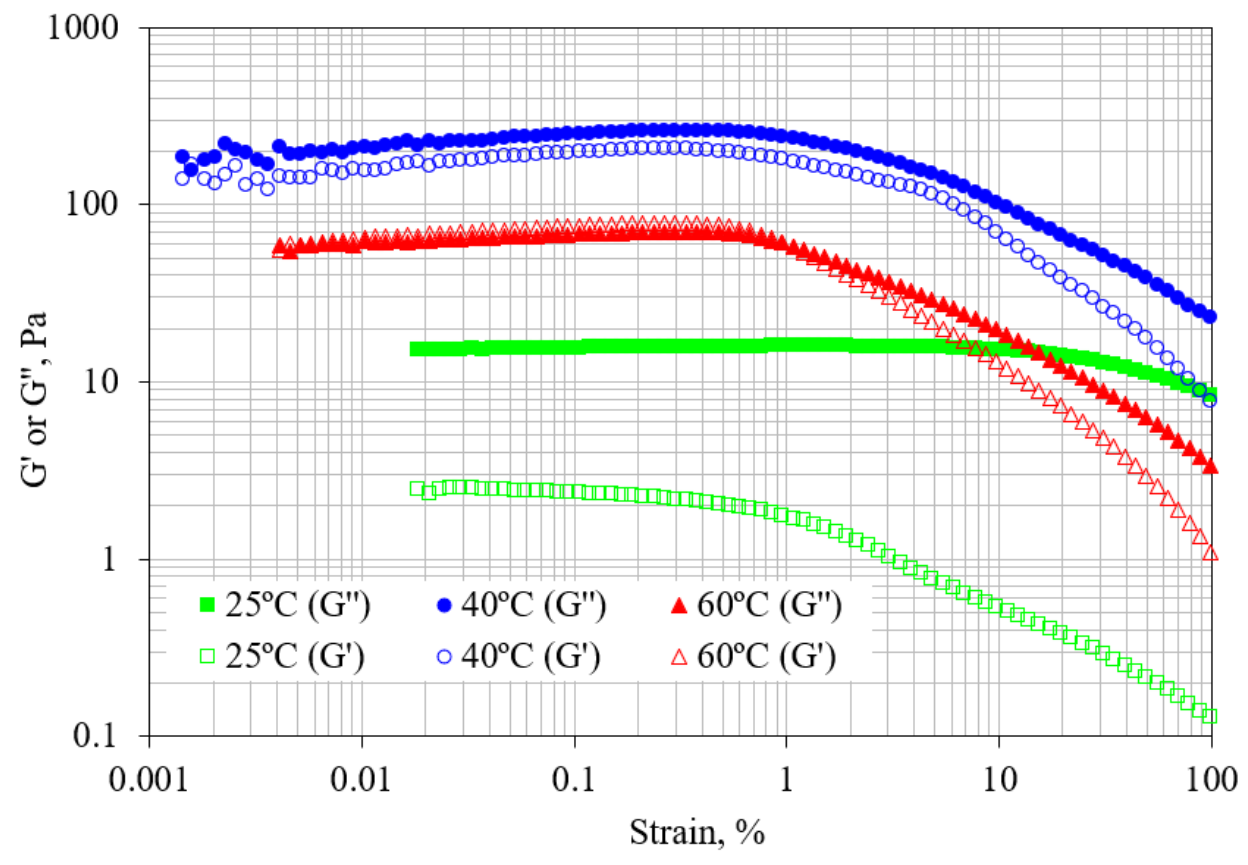

Figure 7: Dynamic strain sweeps at a frequency of $1 \mathrm{~Hz}$ for the bottom phases of the undiluted pyrolysis oils ( 0 wt \%).

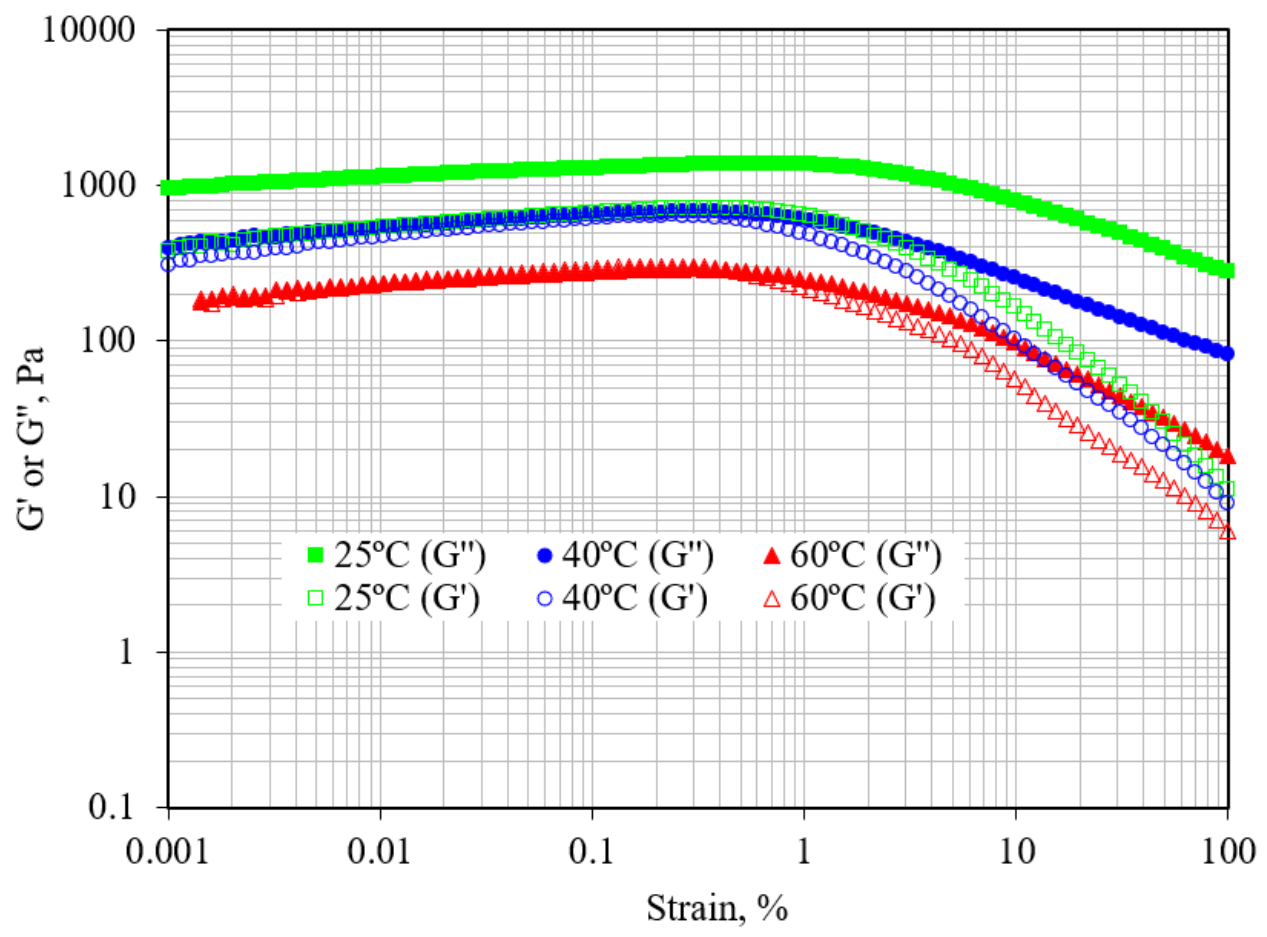

Figure 8: Dynamic strain sweeps at a frequency of $1 \mathrm{~Hz}$ for the bottom phases of the diluted pyrolysis oils (10 wt \%). 


\section{CONCLUSION}

The rheological properties of the pyrolysis oils have been investigated to get background on the behaviour change during storage, handling, transport and application of the oils. The pyrolysis oils exhibit changes in the rheological properties on storage, from simple Newtonian to non-Newtonian behaviours; but the Newtonian behaviour can be recovered at higher temperatures mainly when the oils are under shear forces. The deviation from Newtonian to nonNewtonian behaviours is caused by the formation of heavy aggregated oligomers that produce network structures. However, the structures get broken when the oils are introduced to higher deformation forces, essentially at higher temperatures. This research has found that the unstable oils undergoing faster phase separation exhibit strong non-Newtonian behaviours. This study suggests that the handling, transportation and application of the pyrolysis oils undergoing phase separation are possible when the oils are treated with higher temperatures predominantly in turbulent state.

\section{ACKNOWLEDGMENTS}

NUFU programme is gratefully acknowledged for financing the project, and many thanks to PFI biorefinery project for providing pyrolysis oil.

\section{REFERENCES}

Abdullah H. and Wu H. (2011). Bioslurry as a fuel. 4. Preparation of bioslurry fuels from biochar and the bio-oil-rich fractions after bio-oil/biodiesel extraction. Energy Fuels, 25(4): 1759 1771. https://doi.org/10.1021/ef101535e

Abdullah H., Mourant D., Li C-Z. and Wu H. (2010). Bioslurry as a fuel. 3. Fuel and rheological properties of bioslurry prepared from the bio-oil and biocher of mallee biomass fast pyrolysis. Energy
Fuels, 24(10): $5669-5676$. https://doi.org/10.1021/ef1008117

Ba T., Chaala A., Garcia-Perez M. and Roy C. (2004a). Colloidal properties of bio-oils obtained by vacuum pyrolysis of softwood bark. Storage stability. Energy Fuels, 18(1): 188 - 201. https://doi.org/10.1021/ef0301250

Ba T., Chaala A., Garcìa-Pérez M., Rodrigue D. and Roy C. (2004b). Colloidal properties of bio-oils obtained by vacuum pyrolysis of softwood bark. Characterization of water - soluble and water - insoluble fractions. Energy Fuels, 18(3): $704-712$.

Black S. and Ferrell J.R. III. (2020). Accelerated aging of fast pyrolysis biooil: A new method based on carbonyl titration. RSC Adv., 10(17): 10046 10054. DOI:10.1039/D0RA00046A

Boucher M.E., Chaala A., Pakdel H. and Roy C. (2000). Bio-oils obtained by vacuum pyrolysis of softwood bark as a liquid fuel for gas turbines. Part II: Stability and ageing of bio oil and its blends with methanol and a pyrolytic aqueous phase. Biomass and Bioenergy, 19(5): $\quad 351 \quad-\quad 361$. https://doi.org/10.1016/S09619534(00)00044-1

Bosco A., Calado V. and Maia J. (2019). Rheological parameters of shearthickening fluids using an experimental design. Mat. Res., 22(5). https://doi.org/10.1590/1980-5373-mr2018-0631

Czernik S. and Bridgwater A.V. (2004). Overview of applications of biomass fast pyrolysis oil. Energy Fuels, 18(2): 590-598.

https://doi.org/10.1021/ef034067u

Czernik S., Johnson D.K. and Black S. (1994). Stability of wood fast pyrolysis oil. Biomass and Bioenergy, 7(1-6): 187 $-192$.

Diebold J.P. (2000). A Review of the Chemical and Physical Mechanisms of the Storage Stability of Fast Pyrolysis Bio-Oils. Technical Report for National Renewable Energy Laboratory: 


\section{Rheological Properties of Aged Crude Hard Wood Pyrolysis Oil}

Colorado, USA. Available online at http://www.nrel.gov/docs/fy00osti/2761 3.pdf. Retrieved on $18^{\text {th }}$ May 2021.

Fratini E., Bonini M., Oasmaa A., Solantausta Y., Teixeira J. and Baglioni P. (2006). SANS analysis of the microstructural evolution during the aging of pyrolysis oil from biomass. Langmuir, $22(1): 306-312$. 10.1021/la051990a

Garcìa-Pérez M., Chaala A., Pakdel H., Kretschmer D., Rodrigue D. and Roy C. (2006). Multiphase structure of bio-oils. Energy Fuels, 20(1): 364 - 375. https://doi.org/10.1021/ef050248f

Garcìa-Pérez M., Wang X.S., Shen J., Rhodes M.J., Tian F., Lee W-J., Wu H. and Li C-Z. (2008). Fast pyrolysis of oil mallee woody biomass: effect of temperature on the yield and quality of pyrolysis products. Ind. Eng. Chem. Res., 47(6): $1846 \quad-1854$. https://doi.org/10.1021/ie071497p

Ingram L., Mohan D., Bricka M., Steele P., Strobel D., Crocker D., Mitchel B., Mohammad J., Cantrell K. and Pittman Jr., C.U. (2008). Pyrolysis of wood and bark in an auger reactor: physical properties and chemical analysis of the produced bio-oils. Energy Fuels, 22(1): 614-625. https://doi.org/10.1021/ef700335k

Kaombe D.D., Lenes M., Toven K. and Glomm W.R. (2013). Turbiscan as a tool for studying the phase separation tendency of pyrolysis oil. Energy Fuels, 27(3): $\quad 1446 \quad-\quad 1452$. https://doi.org/10.1021/ef302121r

Jampolski L., Morgano M.T., Seifert H., Kolb T. and Willenbacher N. (2017). Flow behavior and aging of pyrolysis oils from different feedstocks. Energy Fuels, 31(5): 5165 - 5173. https://doi.org/10.1021/acs.energyfuels. $7 \mathrm{~b} 00196$

Mueller S., Llewellin E.W. and Mader H.M. (2010). The rheology of suspensions of solid particles. Proc. of the Royal Society A: $1-28$. https://doi.org/10.1098/rspa.2009.0445
Nolte M.W. and Liberatore M.W. (2010). Viscosity of biomass pyrolysis oils from various feedstocks. Energy Fuels, 24(12): $6601 \quad-\quad 6608$. https://doi.org/10.1021/ef101173r

Nolte M. W. and Liberatore M.W. (2011). Real-time viscosity measurements during the accelerated aging of biomass pyrolysis oil. Energy Fuels, 25(7): 3314-3317.

https://doi.org/10.1021/ef200675t

Oasmaa A. and Czernik S. (1999). Fuel oil quality of biomass pyrolysis oils - state of the art for the end users. Energy Fuels, 13(4): 914 - 921. https://doi.org/10.1021/ef980272b

Oasmaa A. and Kuoppala E. (2003). Fast pyrolysis of forestry residue. 3. Storage stability of liquid fuel. Energy Fuels, 17(4): $\quad 1075 \quad-1084$. https://doi.org/10.1021/ef030011o

Oasmaa A., Fonts I., Pelaez-Samaniego M.R., Garcia-Perez M.E. and GarciaPerez M. (2016). Pyrolysis oil multiphase behavior and phase stability: A Review. Energy Fuels, 30(8): 61796200 .

https://doi.org/10.1021/acs.energyfuels. 6b01287

Panchasara H. and Ashwath N. (2021). Effects of pyrolysis bio-oils on fuel atomisation- A Review. Energies, 14(4): 794. https://doi.org/10.3390/en14040794.

Qiang L., Xu-lai Y. and Xi-Feng Z. (2008). Analysis on chemical and pysical properties of bio-oil pyrolyzed from rice husk. J. Anal. Appl. Pyrolysis, 82: $191-198$.

Qiang, L., Wen-Zhi, L. and Xi-Feng, Z. (2009). Overview of fuel properties of biomass fast pyrolysis oils. Energy Conversion and Management, 50(5): 1376-1383.

https://doi.org/10.1016/j.enconman.200 9.01.001

Raghan S.R. and Khan S.A. (1995). Shearinduced microstructural changes in flocculated suspensions of fumed silica. 
Journal of Rheology, 39(6): 1311 1325. DOI: $10.1122 / 1.550638$

Tangsathitkulchai C., Weerachanchai P. and Tangsathitkulchai M. (2012). Rheology and fuel properties of slurries of char and bio-oil derived from slow pyrolysis of cassava pulp residue and palm shell. Korean J. Chem. Eng., 29: 1713-1721.

https://doi.org/10.1007/s11814-0120046-8

Thangalazhy-Gopakumar S., Adhikari S., Ravindran H., Gupta R.B., Fasina O., $\mathrm{Tu}$ M. and Fernando S.D. (2010). Physiochemical properties of bio-oil produced at various temperatures from pine wood using an auger reactor. Biores. Technol., 101(21): 8389-8395. https://doi.org/10.1016/j.biortech.2010. $\underline{05.040}$

Tzanetakis T., Ashgriz N., James D.F. and Thomson M.J. (2008). Liquid fuel properties of a hardwood-derived bio- oil fraction. Energy Fuels, 22(4): 27252733. https://doi.org/10.1021/ef7007425

Wang R and Ben H. (2020). Accelerated aging process of bio-oil model compounds: A mechanism study. Frontiers in Energy Research, 8: 79. https://doi.org/10.3389/fenrg.2020.0007 $\underline{9}$

Yu F., Deng S., Chen P., Liu Y., Wan Y., Olson A., Kittleson D. and Ruan R. (2007). Physical and chemical properties of bio-oils from microwave pyrolysis of corn stover. Appl. Biochemistry Biotechnol., 137-140(112): 957-970. DOI: $10.1007 / \mathrm{s} 12010-$ 007-9111-X

Zaman A.A., Moudgil B.M., Fricke A.L. and Elshall H. (1996). Rheological behaviour of highly concentrated aqueous silica suspensions in the presence of sodium nitrate and polyethylene oxide. Journal of Rheology, 40(6): 1191 - 1210. https://doi.org/10.1122/1.550781 